\title{
Effects of artificial depletion of the bile acid pool in man
}

\author{
R P JAZRAWI, C BRIDGES, A E A JOSEPH, AND T C NORTHFIELD \\ From the Departments of Medicine, and of Nuclear Medicine and Ultrasound, St. George's Hospital Medical \\ School, London
}

SUMmARY In order to elucidate the relationship between bile acid pool size and cholesterol saturation index of fasting state gall bladder bile, we artifically depleted the bile acid pool in 12 healthy volunteers. Bile acid pool size decreased from $7 \cdot 6 \pm 0 \cdot 9$ to $5 \cdot 8 \pm 0 \cdot 7$ mmol (mean $\pm S E M$, $\mathrm{p}<0.01$ ), and saturation index of fasting state gall bladder bile increased from $0.93 \pm 0.07$ to $1 \cdot 18 \pm 0.07(p<0 \cdot 001)$. There was no alteration in saturation index of basal or stimulated hepatic bile. There was no change in gall bladder storage of basal hepatic bile, nor in the proportion of the bile acid pool stored in the gall bladder. The bile acid mass in the gall bladder fell from $4.9 \pm 0.5$ to $3.4 \pm 0.4 \mathrm{mmol}(\mathrm{p}<0.05)$ and phospholipid mass from $1.6 \pm 0.3$ to $1.2 \pm 0.2 \mathrm{mmol}$ $(\mathrm{p}<0 \cdot 05)$, but there was no change in cholesterol mass. The gall bladder volume fell from $30 \pm 4$ to $18 \pm 2 \mathrm{ml}(\mathrm{p}<0 \cdot 01)$. These results suggest that artificial depletion of the bile acid pool increased saturation index of fasting state gall bladder bile without altering saturation index of basal or stimulated hepatic bile; it probably increased the ratio of basal: stimulated hepatic bile within the gall bladder by decreasing gall bladder storage of stimulated hepatic bile.

Fasting state gall bladder bile of cholesterol gall stone patients differs from that of normal controls by being more saturated with cholesterol. ${ }^{1}$ Excess cholesterol appears to be the cause of this in obese gall stone patients, because biliary cholesterol secretion is increased in obesity. ${ }^{2}$ Bile acid deficiency is the probable cause in non-obese gall stone patients, as bile acid pool size is reduced. ${ }^{3}$ There is an association between a low bile acid pool size and an increased cholesterol saturation index of fasting gall bladder bile, ${ }^{34}$ but the nature of this relationship has not been clearly defined. It has been widely assumed that the connecting link is a reduced hepatic bile acid secretion rate, and results using the constant infusion method of measuring biliary lipid secretion have supported this assumption. ${ }^{4}$ On the other hand, duodenal perfusion studies using the intermittent feeding method, in which the gall bladder is able to contract in response to individual meals, suggest that in subjects with a small bile acid pool this pool recycles more frequently, so that bile acid secretion rate is unchanged. ${ }^{56}$ If this latter concept is correct, it implies that the gall bladder

Address for correspondence: Dr T C Northfield, Department of Medicine. St. George's Hospital Medical School, Cranmer Terrace, London SW17 0RE.

Received for publication 25 June 1985 may play a role in the pathogenesis of cholesterol gall stone disease by increasing recycling frequency, and appropriate abnormalities of gall bladder motor function have been reported in gall stone patients. ${ }^{78}$ A key question is - can gall bladder storage functions alone explain the association between a reduced bile acid pool size and an increased cholesterol saturation index of fasting gall bladder bile without the need to invoke differences in secretion rate?

On the basis of experiments carried out in the baboon, McSherry and colleagues ${ }^{9}$ have pointed out that gall bladder bile comprises a combination of basal and stimulated hepatic bile. Because basal hepatic bile is supersaturated with cholesterol, and stimulated hepatic bile is unsaturated, the net saturation index of gall bladder bile will depend on the relative ratio of basal hepatic bile:stimulated hepatic bile. We speculate that the quantity of stimulated hepatic bile entering the gall bladder after the last meal of the day is likely to depend on the bile acid pool size, so that a reduction in pool size should cause a reduction in the quantity of stimulated hepatic bile in the gall bladder. The gall bladder could respond to this in one of two ways. If gall bladder filling was kept constant so that the quantity of basal hepatic bile entering the gall 
bladder during overnight fasting was unchanged, the net effect of a reduction in bile acid pool size would be to decrease the ratio of stimulated hepatic bile:basal hepatic bile within the gall bladder, and thus to increase saturation index of fasting gall bladder bile and reduce gall bladder volume (Fig. $1 b)$. If gall bladder volume were kept constant, by increasing the volume of basal hepatic bile entering gall bladder so as to compensate for the reduced quantity of stimulated hepatic bile, an even greater effect on saturation index would be obtained (Fig. 1c). In the absence of an alteration in bile acid secretion rate, cholesterol saturation index of basal hepatic bile and stimulated hepatic bile should be unaltered for both models.

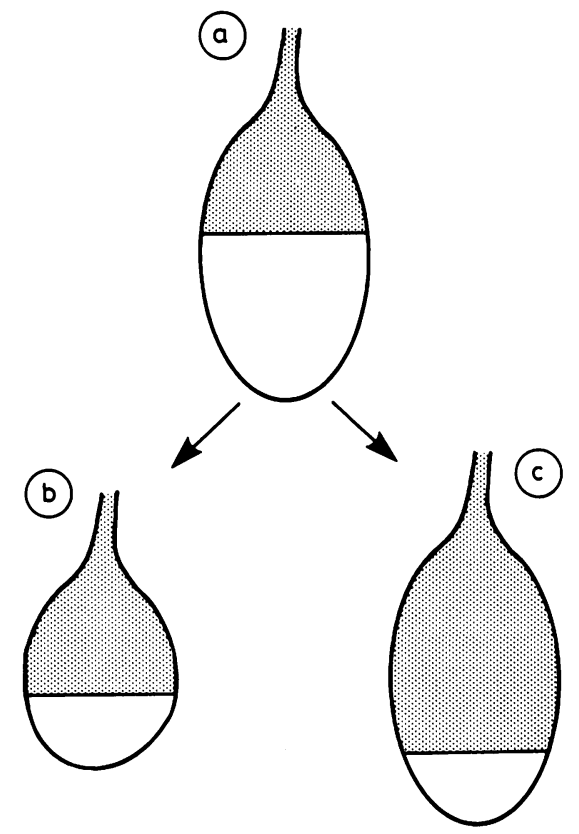

Fig. 1 Hypothetical models of alternative effects of bile acid pool depletion. A represents the relative proportion of basal hepatic bile (BHB; stippled) and of stimulated hepatic bile (SHB; clear) within the gallbladder prior to depletion. In (b) and (c), the amount of SHB entering the gall bladder is reduced due to the smaller bile acid pool size. In (b) gall bladder filling and therefore the amount of $\mathrm{BHB}$ entering the gall bladder are unchanged, so that gall bladder volume is reduced. In (c), gall bladder volume is unchanged, $S H B$ is reduced as in (b), and $B H B$ is increased because of $a$ compensatory increase in fasting state gall bladder filling. In (b) and (c), saturation index of $B H B$ and $S H B$ is unchanged, but the ratio $B H B: S H B$ is increased relative to (a). As $B H B$ is supersaturated with cholesterol and $S H B$ is unsaturated, net cholesterol saturation index is increased in both (b) an (c) relative to (a).
The aim of the present study has been to answer the following questions: does artifical depletion of the bile acid pool in man cause an increase in cholesterol saturation index of fasting gall bladder bile? If so, what is the mechanism? In order to answer these questions we have studied the effect of artificial depletion of the bile acid pool on cholesterol saturation index and on gall bladder storage functions in 12 healthy volunteers.

\section{Methods}

\section{SUBJECTS}

Twelve healthy non-obese male volunteers were studied, aged (mean \pm SEM) $39 \pm 4$ years (range 21-60 years), weight $72 \pm 4 \mathrm{~kg}$ (range $62-100 \mathrm{~kg}$ ), height $171 \pm 2 \mathrm{~cm}$ (range $160-183 \mathrm{~cm}$ ) and \% ideal body weight $99 \pm 3 \%$ (range $86-120 \%$ ). They were all seen in a gastroenterology outpatient clinic complaining of abdominal discomfort, but no evidence of organic disease was found on thorough gastrointestinal investigation, including upper gastrointestinal endoscopy and either ultrasound examination or an oral cholecystogram for exclusion of gall stones. All subjects gave written informed consent for these studies, which were approved by the local hospital ethical committee (April 1980).

Clinical procedures were carried out on two successive days after a 12 hour overnight fast. On day 1 the subjects had an intravenous injection of $1 \mathrm{mCi}$ of ${ }^{99 \mathrm{~m}} \mathrm{Tc}$ HIDA and of $5 \mu \mathrm{Ci}$ carboxyl $-{ }^{14} \mathrm{C}$ chenodeoxycholic acid (Radiochemical Centre, Amersham, Bucks). The gall bladder volume was then determined using ultrasound (Unirad, EDP; 1000 static scanner) and 90 minutes after the initial Tc HIDA injection an abdominal cholescintigram was carried out using a double headed rectilinear scanner with area of interest facility to determine Tc HIDA radioactivity over the gall bladder and gut areas. We have previously validated this as an index of gall bladder filling. " A double lumen polyvinyl nasoduodenal tube was then passed and directed under radiograph screening to the duodenaljejunal flexure. Gall bladder samples were collected after gall bladder contraction was stimulated by a slow intravenous infusion of 100 Ivy Dog Units of cholecystokinin over 30 minutes (Pancreozymin, Boots Ltd.). A sample of basal hepatic bile was taken before the start of gall bladder contraction. The whole sample of gall bladder bile, followed by five samples of stimulated hepatic bile collected at half hour intervals after the cessation of gall bladder contraction (as determined by disappearance of Tc HIDA counts), were retained in order to deplete the bile acid pool. Tc HIDA radioactivity was counted in one gall bladder bile sample in the same way as 
for the subjects' gall bladder in vivo. This sample was used later to determine biliary lipid composition. From this determination and from the radioactivity measurement, it was possible to calculate biliary lipid mass in the gall bladder. All samples were retained for further laboratory analysis. On day 2, the same procedure was carried out, except that (1) $5 \mu \mathrm{Ci}$ of carboxyl- ${ }^{14} \mathrm{C}$ cholic acid was used instead of ${ }^{14} \mathrm{C}$-chenodeoxycholic acid and (2) only one $5 \mathrm{ml}$ sample of gall bladder bile was retained together with the basal hepatic bile and stimulated hepatic bile samples. The radiation exposure to the whole body and to the critical organ was $1.4 \mathrm{mrad}$ and $180 \mathrm{mrad}$ respectively for each of the ${ }^{14} \mathrm{C}$-bile acids, and was $40 \mathrm{mrad}$ and $1430 \mathrm{mrad}$ respectively for ${ }^{99 \mathrm{~m}} \mathrm{Tc}$ HIDA.

\section{LABORATORY METHODS}

Biliary lipid composition was determined using enzymatic analysis of the bile samples for determination of bile acid ${ }^{12}$ and cholesterol ${ }^{13}$ and the perchlorate method for phospholipid determination. ${ }^{14}$ Saturation index was determined according to the criteria of Hegardt and $\mathrm{Dam}^{15}$ and of Holzbach $e a^{16}$ using the polynomial equation of Thomas and Hofmann. ${ }^{17}$

For determination of the bile acid pool size, the bile samples were extracted with ethanol ammonia $1 \%$ solution and subjected to thin layer chromatography to separate the glycine and taurine conjugates of chenodeoxycholic and cholic acid (using chloroform:ethanol:glacial acetic acid:water: 12:8:4:1 v/v as solvent system). ${ }^{14} \mathrm{C}$ radioactivity for chenodeoxycholic acid or cholic acid was determined by liquid scintillation counting, and mass by enzymatic assay in order to obtain the specific activity. This 'one shot' method for measuring bile acid pool size has been shown by Pomare and Low-Beer ${ }^{18}$ to correlate well with the conventional Lindstedt method. ${ }^{19}$

\section{Calculation:}

(1) Gallbladder filling $(\%)=\frac{\mathrm{GBc} \times 100}{\mathrm{GBc}+\text { gutc }}$

Where GBc is the Tc HIDA radioactivity over the gall bladder area, and gutc is the Tc HIDA radioactivity over the gut area.

(2) Biliary lipid mass in the gall bladder was determined using the following formula:

$$
\frac{\mathrm{GBm}}{\mathrm{GBc}}=\frac{\mathrm{Sm}}{\mathrm{Sc}}
$$

Where GBc is the Tc HIDA radioactivity over the gall bladder area and GBm is the mass of bile acid phospholipid or cholesterol in the gall bladder. $\mathrm{Sm}$ is the mass of bile acid, phospholipid or cholesterol in sample, and Sc is the Tc HIDA radioactivity in the sample.

(3) Bile acid concentration in the gall bladder was obtained by dividing bile acid mass in the gall bladder by gall bladder volume.

We have previously described more fully and validated the above measurements of gall bladder filling, biliary lipid mass in the gall bladder and bile acid concentration. ${ }^{11}$

In the present study there was a good agreement between day 1 and day 2 for gall bladder filling (coefficient of variation $12 \%$ ) and for gall bladder emptying (coefficient of variation $9 \%$ ).

\section{STATISTICAL ANALYSIS}

All results are expressed as comparisons of the mean \pm standard error of the mean (SEM). Student's paired $t$ test for significance was calculated where appropriate.

\section{Results}

EFFECT ON POOL SIZE AND BILE ACID

COMPOSITION (Table 1)

Artificial depletion of the bile acid pool was obtained by removal of $2 \cdot 8 \pm 0.4 \mathrm{mmol}$ of bile acid $($ mean \pm SEM; $n=5)$. The measured bile acid pool size fell from $7 \cdot 6 \pm 0.9 \mathrm{mmol}$ on day 1 to $5.8 \pm 0.7 \mathrm{mmol}$ on day $2(\mathrm{p}<0 \cdot 001 ; \mathrm{n}=11)$. This reduction was manifest mainly as a reduction in the mass of the secondary bile acid dexoycholic acid from $1.7 \pm 0.4 \mathrm{mmol}$ to $0.9 \pm 0.3 \mathrm{mmol}(\mathrm{p}<0.005)$. There was a smaller reduction in the mass of the primary bile acids, cholic acid falling from $2 \cdot 7 \pm 0.4 \mathrm{mmol}$ to $2 \cdot 3 \pm 0 \cdot 3 \mathrm{mmol}(\mathrm{NS})$ and chenodeoxycholic acid from $3 \cdot 1 \pm 0 \cdot 2 \mathrm{mmol}$ to $2 \cdot 6 \pm 0 \cdot 3 \mathrm{mmol}(\mathrm{p}<0 \cdot 05)$.

EFFECT ON CHOLESTEROL SATURATION INDEX (Table 2 and Fig. 2)

Artificial depletion of the bile acid pool resulted in an increase in saturation index of fasting gall bladder bile from $0.93 \pm 0.07$ on day 1 to $1 \cdot 18 \pm 0.07$ on day 2 $(\mathrm{p}<0.005)$. There was no change in saturation index of basal hepatic bile collected in the fasting state before initiation of gall bladder contraction (SI of $1 \cdot 46 \pm 0 \cdot 15$ and of $1 \cdot 44 \pm 0 \cdot 11$ respectively). After cessation of gall bladder contraction (indicated by change in colour of bile aspirated from dark green to yellow, confirmed by disappearance of Tc HIDA radioactivity) five samples of stimulated hepatic bile were collected (Fig. 2) at half-hour intervals. There was no significant difference between day 1 and day 2 at any time interval. A steady plateau level was 
Table 1 Pool sizes for total and individual bile acids (mmol) before and after depletion procedure.

\begin{tabular}{|c|c|c|c|c|c|c|c|c|}
\hline \multirow[b]{2}{*}{ Subjects } & \multicolumn{2}{|c|}{ Total bile acids } & \multicolumn{2}{|c|}{ Chenodeoxycholic acid } & \multicolumn{2}{|c|}{ Cholic acid } & \multicolumn{2}{|c|}{ Deoxycholic acid } \\
\hline & Day 1 & Day 2 & Day 1 & Day 2 & Day 1 & Day 2 & Day 1 & Day 2 \\
\hline 1 & $8 \cdot 1$ & $5 \cdot 2$ & 3.4 & $2 \cdot 7$ & $3 \cdot 1$ & $2 \cdot 2$ & 1.6 & 0.5 \\
\hline 2 & $11 \cdot 8$ & $9 \cdot 2$ & $3 \cdot 7$ & 3.7 & $2 \cdot 7$ & $2 \cdot 9$ & $5 \cdot 4$ & $2 \cdot 6$ \\
\hline 3 & $10 \cdot 0$ & 8.9 & $3 \cdot 3$ & $2 \cdot 8$ & $3 \cdot 8$ & $3 \cdot 4$ & 2.9 & $2 \cdot 7$ \\
\hline 4 & $6 \cdot 5$ & $5 \cdot 6$ & $3 \cdot 7$ & $2 \cdot 3$ & 1.4 & $2 \cdot 3$ & $1 \cdot 4$ & $1 \cdot 0$ \\
\hline 6 & $9 \cdot 0$ & $8 \cdot 2$ & $3 \cdot 8$ & $3 \cdot 5$ & $3 \cdot 6$ & $3 \cdot 6$ & 1.6 & $1 \cdot 1$ \\
\hline 7 & $4 \cdot 1$ & $3 \cdot 0$ & $2 \cdot 1$ & $1 \cdot 6$ & 1.4 & $1 \cdot 2$ & 0.6 & $0 \cdot 2$ \\
\hline 8 & $4 \cdot 7$ & $3 \cdot 5$ & 1.9 & $1 \cdot 4$ & $1 \cdot 3$ & $1 \cdot 4$ & $1 \cdot 5$ & 0.7 \\
\hline 9 & $7 \cdot 6$ & $4 \cdot 5$ & $3 \cdot 1$ & $2 \cdot 0$ & $3 \cdot 2$ & $2 \cdot 1$ & $1 \cdot 3$ & 0.4 \\
\hline 10 & 3.9 & $2 \cdot 1$ & $1 \cdot 8$ & $1 \cdot 2$ & $1 \cdot 3$ & 0.6 & 0.8 & 0.3 \\
\hline 11 & 9.9 & $8 \cdot 0$ & $3 \cdot 2$ & $3 \cdot 8$ & $5 \cdot 9$ & $4 \cdot 0$ & 0.8 & 0.2 \\
\hline Mean \pm SEM & $7 \cdot 6 \pm 0.9$ & $5 \cdot 8 \pm 0 \cdot 7$ & $3 \cdot 1 \pm 0 \cdot 2$ & $2 \cdot 6 \pm 3$ & $2 \cdot 7 \pm 0 \cdot 4$ & $2 \cdot 3 \pm 0 \cdot 3$ & $1 \cdot 8 \pm 4$ & $0.9 \pm 3$ \\
\hline $\begin{array}{l}\% \text { change } \\
\text { significance }\end{array}$ & \multicolumn{2}{|c|}{$\begin{array}{l}24 \% \\
p<0.001\end{array}$} & \multicolumn{2}{|c|}{$\begin{array}{l}16 \% \\
p<0.05\end{array}$} & \multicolumn{2}{|c|}{$\begin{array}{l}15 \% \\
\text { NS }\end{array}$} & \multicolumn{2}{|c|}{$\begin{array}{l}50 \% \\
p<0.001\end{array}$} \\
\hline
\end{tabular}

Table 2 Cholesterol saturation index of fasting-state gall bladder bile and of hepatic bile (basal and stimulated) before and after depletion of bile acid pool

\begin{tabular}{|c|c|c|c|c|c|c|}
\hline \multirow[b]{2}{*}{ Subjects } & \multicolumn{2}{|c|}{ Gall bladder bile } & \multicolumn{2}{|c|}{ Basal hepatic bile } & \multicolumn{2}{|c|}{ Stimulated hepatic bile } \\
\hline & Day 1 & Day 2 & Day 1 & Day 2 & Day 1 & Day 2 \\
\hline 1 & 1.07 & 1.35 & - & - & - & - \\
\hline 2 & $1 \cdot 08$ & $1 \cdot 77$ & - & - & - & - \\
\hline 3 & 0.79 & 1.02 & 1.40 & 1.40 & $0 \cdot 62$ & 0.47 \\
\hline 4 & 0.90 & 1.40 & $1 \cdot 30$ & $1 \cdot 50$ & $0 \cdot 80$ & $0 \cdot 86$ \\
\hline 5 & $0 \cdot 72$ & 1.09 & $1 \cdot 50$ & $1 \cdot 58$ & 0.45 & $0 \cdot 76$ \\
\hline 6 & 1.06 & $1 \cdot 30$ & $1 \cdot 12$ & $1 \cdot 12$ & 0.49 & $0 \cdot 39$ \\
\hline 7 & $0 \cdot 84$ & $1 \cdot 37$ & 1.43 & $1 \cdot 14$ & $0 \cdot 46$ & 0.75 \\
\hline 8 & $0 \cdot 84$ & 0.95 & $1 \cdot 23$ & $1 \cdot 35$ & $0 \cdot 74$ & 0.71 \\
\hline 9 & $1 \cdot 40$ & 1.42 & $2 \cdot 30$ & $2 \cdot 18$ & $1 \cdot 25$ & $0 \cdot 77$ \\
\hline 10 & $0 \cdot 55$ & $0 \cdot 66$ & $0 \cdot 96$ & $1 \cdot 10$ & $0 \cdot 52$ & $0 \cdot 34$ \\
\hline 11 & 0.76 & $1 \cdot 20$ & 1.90 & $1 \cdot 60$ & $0 \cdot 27$ & 0.62 \\
\hline Mean \pm SEM & $0.93 \pm 0.07$ & $1 \cdot 18 \pm 0.07$ & $1 \cdot 46 \pm 0.15$ & $1 \cdot 44 \pm 0 \cdot 11$ & $0.62 \pm 0.09$ & $0.63 \pm 0.06$ \\
\hline significance & \multicolumn{2}{|c|}{$\mathrm{p}<0.005$} & \multicolumn{2}{|c|}{ NS } & \multicolumn{2}{|c|}{ NS } \\
\hline
\end{tabular}

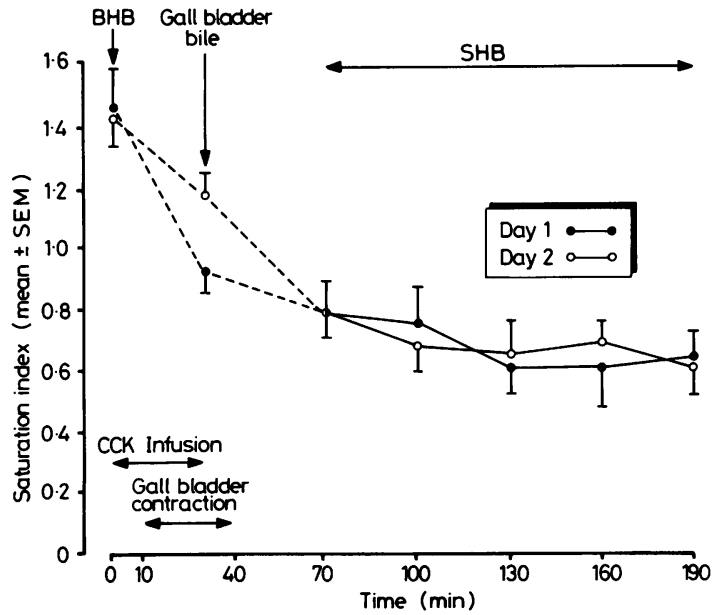

Fig. 2 Saturation index of successive bile samples on day 1 and day 2 , representing in sequence basal hepatic bile, fasting gall bladder bile and sequential aliquots of stimulated hepatic bile obtained at 30 minute intervals. reached for the last three samples $(130,160$ and 190 minutes), suggesting a maximum effect on saturation index due to increased hepatic bile acid flux on both days, and the value for stimulated hepatic bile used in Table 2 is the mean value for these three successive half-hourly measurements.

\section{EFFECT ON GALLBLADDER STORAGE FUNCTION (Tables 3 and 4)}

(a) On day 1, gall bladder filling with basal hepatic bile was $55 \pm 8 \%$ and on day 2 it was $47 \pm 6 \%$ (NS).

(b) After depletion of the bile acid pool, the gall bladder volume was reduced in all subjects from $30 \pm 4 \mathrm{ml}$ on day 1 to $18 \pm 2 \mathrm{ml}$ on day $2(\mathrm{p}<0.05)$.

(c) There was a reduction in the bile acid mass within the gall bladder from $4.9 \pm 0.5 \mathrm{mmol}$ on day 1 to $3.4 \pm 0.4 \mathrm{mmol}$ on day $2(\mathrm{p}<0.05)$, and of phospholipid mass from $1 \cdot 6 \pm 0 \cdot 2 \mathrm{mmol}$ to $1 \cdot 1 \pm 0 \cdot 2$ mmol, $(\mathrm{p}<0.05)$. There was no significant reduction in cholesterol mass $(0.47 \pm 0.09 \mathrm{mmol} v s 0.43 \pm 0.06$ 
Table 3 Mass of bile acid, phospholipid and cholesterol in the fasting state gall bladder before and after depletion of the bile acid pool

\begin{tabular}{|c|c|c|c|c|c|c|}
\hline \multirow[b]{2}{*}{ Subjects } & \multicolumn{2}{|c|}{ Bile acids (mmol) } & \multicolumn{2}{|c|}{ Phospholipid (mmol) } & \multicolumn{2}{|c|}{ Cholesterol (mmol) } \\
\hline & Day 1 & Day 2 & Day 1 & Day 2 & Day 1 & Day 2 \\
\hline 1 & $5 \cdot 16$ & $3 \cdot 48$ & $1 \cdot 20$ & 0.64 & $0 \cdot 43$ & $0 \cdot 23$ \\
\hline 2 & 8.73 & $4 \cdot 88$ & $1 \cdot 35$ & $1 \cdot 39$ & $0 \cdot 96$ & $0 \cdot 64$ \\
\hline 3 & $6 \cdot 64$ & $5 \cdot 62$ & $2 \cdot 81$ & $2 \cdot 34$ & 0.49 & $0 \cdot 55$ \\
\hline 4 & $5 \cdot 35$ & 4.00 & 3.00 & 0.98 & 0.97 & $0 \cdot 68$ \\
\hline 5 & 3.79 & $2 \cdot 80$ & $0 \cdot 85$ & $0 \cdot 80$ & $0 \cdot 14$ & $0 \cdot 27$ \\
\hline 6 & $4 \cdot 59$ & $4 \cdot 06$ & $1 \cdot 14$ & $1 \cdot 16$ & 0.40 & 0.54 \\
\hline 7 & $3 \cdot 67$ & $2 \cdot 52$ & 0.94 & 0.85 & 0.23 & $0 \cdot 31$ \\
\hline 8 & 3.74 & $2 \cdot 98$ & $2 \cdot 07$ & 1.65 & $0 \cdot 33$ & 0.45 \\
\hline 9 & $5 \cdot 44$ & $2 \cdot 44$ & 1.54 & $1 \cdot 32$ & 0.73 & $0 \cdot 58$ \\
\hline 10 & $1 \cdot 80$ & 1.08 & 0.53 & $0 \cdot 34$ & $0 \cdot 81$ & $0 \cdot 72$ \\
\hline Mean \pm SEM & $4 \cdot 93 \pm 0 \cdot 51$ & $3 \cdot 39 \pm 0 \cdot 42$ & $1 \cdot 61 \pm 0 \cdot 25$ & $1 \cdot 15 \pm 0 \cdot 18$ & $0 \cdot 47 \pm 0 \cdot 09$ & $0 \cdot 43 \pm 0 \cdot 06$ \\
\hline significance & \multicolumn{2}{|c|}{$\mathrm{p}<0.005$} & \multicolumn{2}{|c|}{$\mathrm{p}<0.05$} & \multicolumn{2}{|c|}{ NS } \\
\hline
\end{tabular}

Table 4 Effect of bile acid (BA) pool depletion of gall bladder storage functions

\begin{tabular}{|c|c|c|c|c|c|c|}
\hline \multirow[b]{2}{*}{ Subjects } & \multicolumn{2}{|c|}{ Gall bladder filling (\%) } & \multicolumn{2}{|c|}{ Gall bladder volume $(\mathrm{ml})$} & \multicolumn{2}{|c|}{$\begin{array}{l}\text { BA concentration in gall } \\
\text { bladder (mmolll) }\end{array}$} \\
\hline & Day 1 & Day 2 & Day 1 & Day 2 & Day $I$ & Day 2 \\
\hline 1 & 67 & 64 & $35 \cdot 8$ & $21 \cdot 7$ & $144 \cdot 2$ & $160 \cdot 4$ \\
\hline 2 & 57 & 36 & $45 \cdot 8$ & $26 \cdot 6$ & $190 \cdot 6$ & 183.4 \\
\hline 3 & 24 & 41 & $33 \cdot 5$ & $19 \cdot 5$ & $198 \cdot 2$ & $288 \cdot 3$ \\
\hline 4 & 71 & 48 & - & - & - & - \\
\hline 5 & 25 & 33 & $36 \cdot 8$ & $15 \cdot 2$ & $103 \cdot 0$ & 183.9 \\
\hline 6 & 31 & 31 & - & - & - & - \\
\hline 7 & 91 & 68 & $15 \cdot 4$ & $11 \cdot 4$ & $238 \cdot 5$ & $221 \cdot 2$ \\
\hline 8 & 64 & 71 & $21 \cdot 5$ & $16 \cdot 3$ & 173.8 & $182 \cdot 8$ \\
\hline 9 & 84 & 5 & $36 \cdot 2$ & $15 \cdot 0$ & $150 \cdot 1$ & $154 \cdot 6$ \\
\hline 10 & 13 & 6 & $17 \cdot 6$ & $15 \cdot 8$ & $102 \cdot 3$ & $68 \cdot 2$ \\
\hline 11 & 45 & - & - & - & - & - \\
\hline 12 & 77 & 67 & $26 \cdot 1$ & $18 \cdot 2$ & - & - \\
\hline Mean \pm SEM & \multirow{2}{*}{\multicolumn{2}{|c|}{$4 / \pm 6$}} & $30 \pm 4$ & $18 \pm 2$ & $163 \pm 16$ & $180 \pm 21$ \\
\hline significance & & & \multicolumn{2}{|c|}{$p<0.05$} & \multicolumn{2}{|c|}{ NS } \\
\hline
\end{tabular}

mmol). Bile acid mass in the gall bladder correlated well with gall bladder volume on both days $(r=0 \cdot 81$, $\mathrm{p}<0.01 ; \mathrm{r}=0.73, \mathrm{p}<0.05$ on day 1 and day 2 respectively).

(d) There was no difference in per cent bile acid pool in the gall bladder after depletion of the pool $(66 \cdot 5 \pm 4 \cdot 6 \%$, and $69 \cdot 7 \pm 4 \cdot 3 \%$ on days 1 and 2 respectively).

(e) Bile acid concentration within the gall bladder was $163 \pm 16 \mathrm{mmol} / \mathrm{l}$ on day 1 and $180 \pm 21 \mathrm{mmol} / \mathrm{l}$ on day 2 (NS).

Some of the results are missing on Table 4, mainly because the rectilinear scanner was out of action on day 2 for subject number 11 and the ultrasound being out of action for subjects 4 and 6 . Also subject number 12 failed to give a bile sample on day 2 .

\section{Discussion}

In our study, depletion of the bile acid pool was followed by an increase in cholesterol saturation index of gall bladder bile from $0.93 \pm 0.07$ to $1 \cdot 18 \pm 0.07(\mathrm{p}<0.005)$. This increase in saturation index was because of a reduction in bile acid and phospholipid mass within the gall bladder without an equivalent reduction in cholesterol mass (Table $3)$. It was not the result of an increase in saturation index of basal hepatic bile or of stimulated hepatic bile, which was unchanged (Fig. 2 and Table 2). These findings would fit for either model $\mathrm{B}$ or model $\mathrm{C}$ in Figure 1. The fact that gall bladder volume was significantly reduced, whereas fasting state gall bladder filling and the proportion of the bile acid pool stored in the gall bladder overnight were unchanged, is consistent with model B but not with model C. The mean depletion in bile acid pool obtained in this study was $24 \%$, whereas Vlahcevic et $a l^{3}$ found that the mean reduction in bile acid pool size in eight male gall stone patients was $46 \%$ compared with nine male controls. The increase in gall bladder bile saturation index in our non-obese 
male subjects $(27 \%)$ was similar to the degree of depletion of the bile acid pool $(24 \%)$ in our study. In obese gall stone patients, increased cholestrol secretion, not reduced bile acid pool size, is the mechanism for the increased saturation index of gall bladder bile.

We cannot exclude the possibility that an increase in saturation index of hepatic bile entering the gall bladder on the evening before the second day sample might have contributed to the increased saturation index of fasting gall bladder bile next morning. The fact that in all our subjects basal hepatic bile on the second morning was not altered, and stimulated hepatic bile measured on serial samples on the second day was also unaltered makes this possibility unlikely. Moreover, even if this possibility were correct, it cannot provide an alternative explanation to our model, but only an additional explanation. Further evidence in favour of our model (Fig. 1b) is provided by finding similar mean reductions in total bile acid pool size $(24 \%)$, gall bladder bile acid mass $(31 \%)$ and gall bladder volume $(40 \%)$ after depletion. Although fasting gall bladder volume was not significantly different in 34 gall stone patients and in 34 matched controls, as assessed by carefully standardised oral cholecystography, ${ }^{20}$ this comparison took no account of the volume occupied by the gall stones. If this volume is subtracted, so as to give the volume occupied by gall bladder bile in both cases, the volume is reduced by a mean value of $14 \%$ in the gall stone patients by comparison with the control values $(p<0.02$, unpublished data).

Our method of measuring gall bladder filling has already been validated in normal subjects, ${ }^{11}$ and results in 12 healthy controls were found to be similar to those obtained by other authors using a duodenal perfusion technique. ${ }^{21} 22$ Furthermore, duplicate studies in five subjects gave values which varied by $1-8 \%$ with $95 \%$ confidence limit of $11 \%$. Gall bladder filling in the present study was comparable on day 1 and day 2, (coefficient of variation $12 \%$ ). The one exception to this (subject number 9) had a considerable difference in gall bladder filling between the two days, probably because of spontaneous gall bladder contraction at the time of measurement. The detection of very minor gall bladder filling (5\% and $6 \%$ ) in subjects 9 and 10 respectively (Table 4) implies that most of the Tc HIDA radioactivity was not in the gall bladder. Thus, when gall bladder bile was aspirated and its Tc HIDA radioactivity used to estimate biliary lipid mass within the gall bladder, the results might be inaccurate if contaminated with Tc HIDA in the duodenum. The fact that we allowed 90 minutes between the bolus injection of Tc HIDA and gall bladder contraction should have enabled the Tc HIDA that cleared the liver and was not sequestered into gall bladder to move down the intestine beyond the aspiration site by the time of gall bladder contraction. Furthermore, in both subjects the low value for gall bladder filling was on the second day, and in both subjects the bile acid pool size and bile acid mass in the gall bladder were reduced to the same relative extent as in the other subjects.

Artificial depletion of the bile acid pool in our subjects involved removal on average of $41 \%$ of the initial bile acid pool, and deoxycholic acid pool remained depleted by a similar amount on day 2 (mean of $50 \%, r=0.77, \mathrm{p}<0.05$ ). The total bile acid pool was only reduced by a mean of $24 \%$ on day 2 and this reduction correlated with the reduction in bile acid mass in the gall bladder on day 2 of $31 \%$ on average $(r=0 \cdot 72, p<0 \cdot 01)$. The measured reduction in pool size the two primary bile acids (chenodeoxycholic acid and cholic acid) was only 14 and $15 \%$ respectively, presumably because of new bile acid synthesis during the 24 hour period. The method we used for measuring bile acid pool size was the one shot dilution technique used by Pomare and Low Beer ${ }^{18}$ which they found to correlate well with the Lindstedt technique. We were unable to use the Lindstedt technique ${ }^{19}$ because of the need to carry out independent measurements of the bile acid pool size on the two consecutive days. For the same reason we had to use two different labelled bile acids $\left({ }^{14} \mathrm{C}\right.$ chenodeoxycholic acid and ${ }^{14} \mathrm{C}$ cholic acid) so as to avoid artefact in the day 2 measurement due to radioactivity remaining from day 1 .

Mok and colleagues ${ }^{23}$ have also shown that artificial depletion of the bile acid pool results in an increase in saturation index of fasting state gall bladder bile in human volunteers. They observed that during their depletion procedure, which involved removal of 40 to $60 \%$ of the bile acid pool, there was a significant reduction in the hepatic secretion rate for bile acid and phospholipid but a less marked drop in cholesterol secretion. This is in keeping with the results of Dowling and colleagues in the rhesus monkey, ${ }^{24}$ where it was clearly shown that artificial interruption of the enterohepatic circulation of bile acids by more than $20 \%$ causes hepatic secretion of supersaturated bile. This immediate effect of acute interruption of the enterohepatic circulation of bile acids, as shown by Mok and colleagues, ${ }^{23}$ must be distinguished from the delayed effect of depletion of the bile acid pool, as studied by us. Our studies were repeated at an interval of 24 hours after the depletion procedure, and by this time we were unable to detect any alteration in saturation index of hepatic bile in either 
the basal or stimulated samples. In this situation, the observed increase in saturation index of fasting state gall bladder bile can only be attributed to an increased ratio of basal:stimulated hepatic bile, as suggested by our other measurements.

We would like to express our gratitude to Mr Robert Bird and Mrs Moya Gannon for their technical assistance and also to Miss Marion Amos for her excellent secretarial assistance.

\section{References}

1 Admirand WH, Small DM. The physicochemical basis of cholesterol gallstone formation in man. J Clin Invest 1968; 47: 1043-52.

2 Shaffer EA, Small DM. Biliary lipid secretion in cholesterol gallstone disease: The effect of cholecystectomy and obestiy. J Clin Invest 1977; 59: 828-40.

3 Vlahcevic ZR, Bell CC jr, Buhac I, Farrar JT, Swell L. Diminished bile acid pool size in patients with gallstones. Gastroenterology 1970, 59: 165-73.

4 Grundy SM, Metzger AL. A physiological method for estimation of hepatic secretion of biliary lipids in man. Gastroenterology 1972; 62: 1200-17.

5 Northfield TC, Hofmann AF. Biliary lipid secretion in gallstone patients. Lancet 1973; 1: 747-8.

6 Northfield TC, Hofmann AF. Biliary lipid output during three meals and an overnight fast. 1. Relationship to bile acid pool and cholesterol saturation of bile in gallstone and control subjects. Gut 1975; 16: 1-7.

7 Maudgal DP, Kupfer RM, Zentler Munro PL, Northfield TC. Postprandial gallbladder emptying in patients with gallstones. $\mathrm{Br}$ Med J 1980; 2809: 141-3.

8 Northfield TC, Kupfer RM, Maudgal DP, et al. Gallbladder sensitivity to cholecystokinin in patients with gallstones. $\mathrm{Br}$ Med $J$ 1980; 280: 143-5.

9 McSherry CK, Glenn F, Javitt NB. Composition of basal and stimulated hepatic bile in baboons, and the formation of cholesterol gallstone. Proc Natl Acad Sci 1971; 68: 1564-8.

10 Everson GT, Braverman DZ, Johnson MW, Kern F. A critical evaluation of real-time ultrasonography for the study of gallbladder volume and contraction. Gastroenterology 1980; 79: 40-6.

11 Jazrawi RP, Kupfer RM, Bridges C, Joseph A, Northfield TC. Assessment of gallbladder function in man. Clin Sci 1983; 65: 185-91.

12 Talalay P. Enzymatic analysis of sterol hormones. Methods Biol Anal 1960; 8: 119-43.

13 Roda A, Festi D, Sama C, et al. Enzymatic determination of cholesterol in bile. Clin Chim Acta 1975; 64: 337-41.

14 Bartlett P. Phosphorus assay in column chromatography. J Biol Chem 1959; 234: 466-8.

15 Hegardt FG, Dam H. The solubility of cholesterol in aqueous solutions of bile salts and lecithin. Z Ernahrungswiss 1971; 10: 223-33.

16 Holzbach RT, Marsh M, Olszcwski M, Holan K. Cholesterol solubility in bile: evidence that supersaturated bile is frequent in healthy man. $J$ Clin Invest 1973; 52: 1467-9.

17 Thomas PJ, Hofmann AF. A simple calculation of the lithogenic index of bile: expressing biliary lipid composition on rectangular co-ordinates. Gastroenterology 1973; 65: 698-700.

18 Pomare EW, Low-Beer TS. Measurement and validation of human bile acid pool size and synthesis. Clin Chim Acta 1974; 57: 239-48.

19 Linstedt S. The turnover of cholic acid in man. Acta Physiol Scand 1957; 40: 1-9.

20 Maudgal DP, Kupfer RM, Zentler-Munro PL, Northfield TC. Postprandial gall-bladder emptying in patients with gallstones. $\mathrm{Br}$ Med J 1980; 30: 141-5.

21 Mok HYI, Von Bergemann K, Grundy SM. Effects of continuous and intermittent feeding on biliary lipid outputs in man. Application of intestinal absorption of cholesterol and bile acids. J Lipid Res 1979; 20: 389-98.

22 Van Berge Henegouwen GP, Hofmann AF. Nocturnal gallbladder storage and emptying in gallstone patients and healthy subjects. Gastroenterology 1978; 75: 879-85.

23 Mok HYI, van Bergmann K, Grundy SM. Effects of interruption of enterohepatic circulation on biliary lipid secretion in man. Dig Dis 1978; 23: 1067-75.

24 Dowling RH, Mack E, Small DM. Primate biliary physiology. IV Biliary lipid secretion and bile composition after acute and chronic interruption of the enterohepatic circulation in the rhesus monkey. J Clin Invest 1971; 50: 1917-26. 